\title{
SC|A2
}

\section{Os desafios da mulher empreendedora em tempos de pandemia (COVID-19) e o enfrentamento em conciliar: família e trabalho}

\section{Resumo}

Alessandra Nascimento Pontes ${ }^{1}$ Gesyca Patrícia da Silva Santos ${ }^{2}$

Noemi Mello Loureiro3 Jaqueline Maria da Silva4

O marco histórico dos direitos conquistados pelas mulheres no mundo retrata o processo de construção de lugar de fala da mulher. Bem como, ressalta o desenvolvimento do papel da mulher contemporânea frente às atividades desempenhadas. Nesse sentido, o presente estudo tem por objetivo refletir sobre o marco histórico das conquistas femininas e a sua ressignificação na contemporaneidade em tempos de pandemia, bem como, mostrar as adversidades encontradas nos seus papeis, de mãe; docente; cientista e empreendedora. Inicialmente, procedeu-se a busca aleatória de artigos científicos e livros por meio de busca eletrônica. Trata-se de um estudo do tipo relato de experiência, de natureza descritiva, com abordagem reflexiva, de pesquisadoras de várias áreas do conhecimento, pertencentes a instituições públicas e privadas de ensino superior. O levantamento realizado no período de junho a julho de 2020. As reflexões epistemológicas contemporânea das

Doutoranda pela Universidade Presbiteriana Mackenzie-Distúrbios do Desenvolvimento. Atualmente desempenha suas atividades na área Acadêmicas no Centro Universitário CESMAC tanto na Gestão como na Graduação em Enfermagem. Atualmente, é responsável pela Startup Risk Life, Haviso e Touch Brasil.

E-mail: profanpontes@gmail.com

${ }^{2}$ Mestranda em Propriedade Intelectual e Transferência de Tecn para Inovação PROFNIT /UFAL, Atualmente, faz parte do Projeto Coletivo que atende o grupo de Startups, com objetivo promover o desenvolvimento sustentável e o fortalecimento dos Negócios Digitais, coordenado pelo SEBRAE/Al.

E-mail: gesycasantos13@gmail.com

${ }^{3}$ Doutoranda pela Universidade Presbiteriana Mackenzie-Distúrbios do Desenvolvimento. Graduação em Pedagogia pela Fundação Educacional Jayme de Altavilla - FEJAL(2002). Atualmente é Professora do Curso de Licenciatura em Dança da UFAL.

E-mail: noemiloureirodanca@gmail.com

${ }^{4}$ Pós-doc em Química e Biotecnologia pelo Instituto de Química e Biotecnologia-UFAL. Atualmente é Profa Titular III do Curso de Enfermagem, Líder do GP Biotec. e Tecnologia Aplicada à Saúde; Coord. da Liga Acad. de Educação e Saúde (LAES) e Membro da Comissão de Biossegurança da Faculdade CESMAC do Sertão.

E-mail: jaqueline.silva@cesmac.edu.br 
conquistas femininas embasam o discurso, de modo a impactar em sua produtividade acadêmica.

\section{Palavras-chave}

Feminina. Docente. Pesquisadora. COVID-19.

Recebido em: 31/07/2020

Aprovado em: 26/01/2021

\section{Pedagogical relations in times of Digital Culture: New ways of Learning and Teaching}

\section{Abstract}

The historical landmark of the rights conquered by women in the world portrays the process of building a place for women to speak. As well as, it highlights the development of the role of contemporary women in relation to the activities performed. In this sense, this study aims to reflect on the historical milestone of women's conquests and their resignification in contemporary times in pandemic times, as well as showing the adversities found in their roles as mothers; teacher; scientist and entrepreneur. Initially, a random search of scientific articles and books was carried out by means of electronic search. This is a descriptive study, of a descriptive nature, with a reflective approach, of researchers from various areas of knowledge, belonging to public and private institutions of higher education. The survey carried out from June to July 2020. The contemporary epistemological reflections of women's achievements are the basis of the discourse, in order to impact their academic productivity.

\section{Keywords}

Feminine. Teacher. Researcher. COVID-19. 


\section{Introdução}

O marco histórico das conquistas femininas perpassa os hemisférios com militâncias e teorias que se tornaram publicas na segunda metade do século XX, com manifestações na Inglaterra, Londres e Reino unido em meados dos anos de 1913 a 1918 (PINTO, 2010). No Brasil as manifestações também eram intensas, mas o marco histórico do feminismo foi à criação do Conselho Nacional da Condição da Mulher (CNDM), em 1984. Ao longo dos anos leis de proteção a mulher foi criada como a lei Maria da Penha (Lei n. 11340, de 7 de agosto de 2006), que criou mecanismos para coibir a violência doméstica e familiar contra a mulher; Lei $\mathrm{n}^{0} 13.104$ o feminicídio; Lei $\mathrm{n}^{0}$ 1.718/2018 o assédio como crime, entre outras.

A mulher há décadas tem sido a maior força de trabalho na saúde, dados censitários do Brasil foram evidenciados demonstrando que cerca de 90,39\% dos trabalhadores são mulheres (WERMELINGER et al.2010).

As mulheres não estão apenas nas linhas de frente, como também, na responsabilidade das tomadas de decisão relativas a essa pandemia, nas instancias locais, estaduais, regionais, nacionais e internacionais (MATOS, 2020).

Há 58 anos as mulheres não podiam trabalhar, imagine tendênciar ao empreendedorismo, mas a lei Lei $n^{0}$ 4.212/1962 autoriza o trabalho feminino, que oportunizou ao empreendedorismo feminino nos anos seguintes. Atualmente, o Brasil tem a $7^{\mathrm{a}}$ maior proporção de mulheres entre os empreendedores iniciais, significa que 9,3 milhões de mulheres são donas do seu negócio, com uma motivação principal "necessidade", o Sebrae buscou traçar o perfil dessas mulheres empreendedoras que são: mulheres mais jovens, tem maior escolaridade, chefes de domicílio, tem apenas um trabalho e $75 \%$ estão a mais de 2 anos, a maioria não tem sócio, dentre outros (IBQP, 2018).

A adoção de novos parâmetros tecnológicos frente à realidade vivenciada pela mulher no seu dia-a-dia, demonstra a sua flexibilização adaptativa, ao uso das 
tecnologias de informação e comunicação - TICs, para o trabalho, educação ou família. Alcantara\& Lima (2019) evidenciam o impossível educar na cibercultura independente do gênero. Dedoné (2019) demonstra que a educomunicação é uma práxis social, uma realidade prática de cidadania.

O presente trabalho reflete a peleja da mulher empreendedora, cientista, docente, pesquisadora em ter que alinhar sua rotina de trabalho com a de mãe. Este relato está dividido em duas partes a primeira traz um marco histórico de todo os direitos conquistados pela mulher, tendo a intenção de criar um cenário que permita compreender o processo de construção e ressignificação do papel da mulher pesquisadora. Na segunda parte, evidencio os relatos de experiências vivenciados durante a pandemia. Neste sentido, faz-se relevante refletir sobre o marco histórico das conquistas femininas e a sua ressignificação na contemporaneidade em tempos de pandemia.

\section{Do marco histórico ao ressignificar o trabalho da mulher durante a pandemia}

Há muitos anos mulheres vêm lutando por igualdade de gênero e não podemos deixar de citar os grandes movimentos que fizeram com que direitos fossem conquistados, como: o feminismo e sufragismo. Nessa linha de pensamento a autora Ana Colling afirma que: "O século XIX, que moldou a nossa modernidade, assiste também a modificações nas relações entre homens e mulheres. As mulheres, acreditando na universalidade da igualdade, perseguem e lutam ferozmente pela sua cidadania social e política, [...]”. (COLLING, 2004, p. 16).

Por décadas, mulheres foram restritas a participarem de decisões importantes e principalmente proibidas de questionar qualquer coisa e nesse processo muitas sofreram e outras por questionar pagaram com a própria vida, como é o caso da Joana D'arc que lutou até a morte em 1429 incansavelmente contra a ocupação inglesa na França, nesta época a igreja católica tinha instaurado um tribunal de inquisição para aqueles que não seguiam os mandamentos da igreja estes, eram considerados hereges, "bruxas", feiticeiras", qualquer pessoa do gênero feminino, especialmente, que manifestar-se seus pensamentos contrário ao da 
igreja ou que lutassem por algum direito, fossem eles religiosos, políticos ou social eram submetidas a interrogatórios cruéis chegando ao ponto de serem queimadas vivas em meio a praça pública.

Assim, vem sendo discutidos nas últimas décadas e precisamente no século XX e intensamente afirmados no século XXI com alguns direitos conquistados através de lutas seculares, como bem, pode ser visualizada na linha do tempo logo a baixo. 


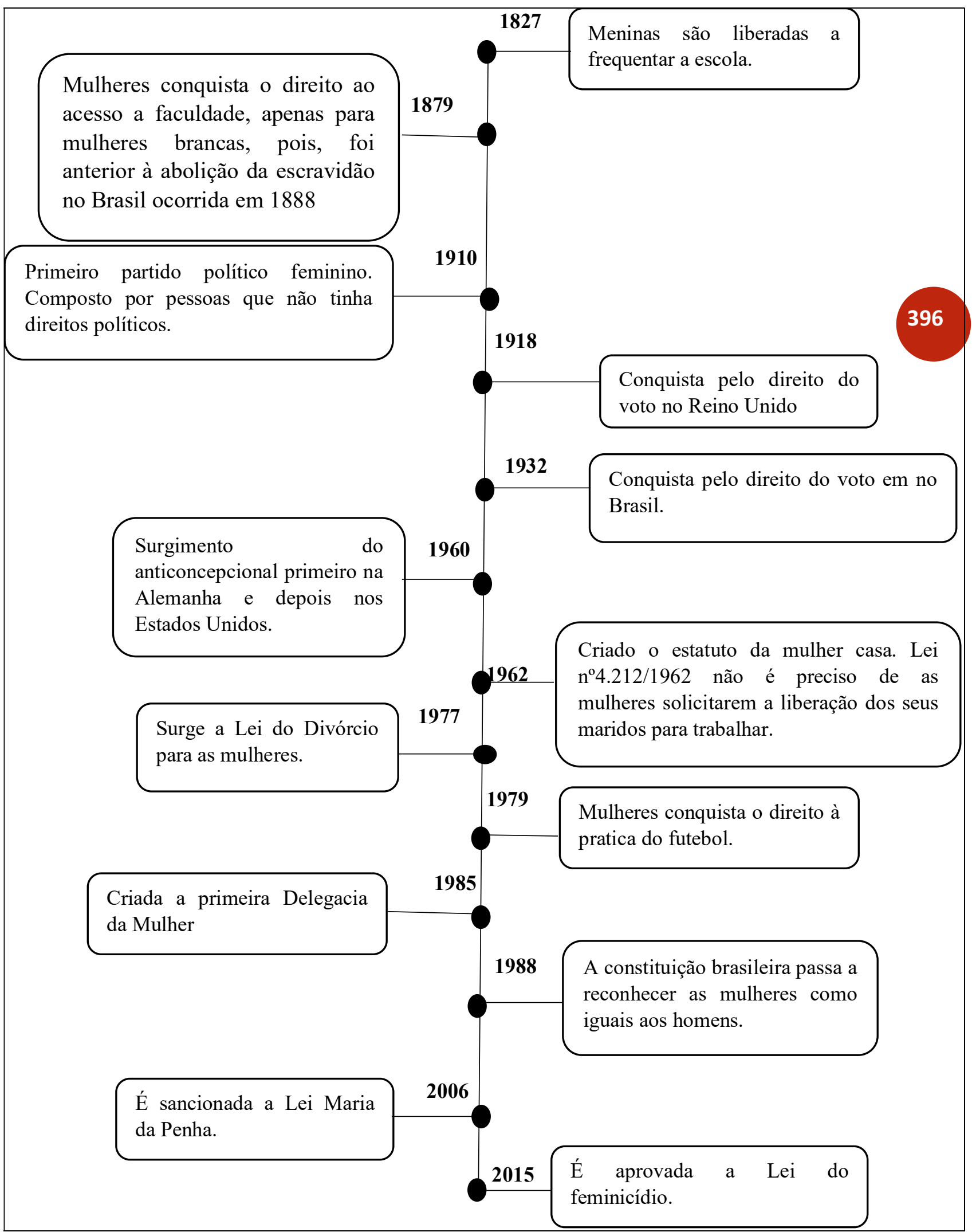

Fonte: Autoria própria (2020).

Mas, com tantas conquistas a serem comemoradas, ainda, infelizmente vivemos numa sociedade patriarcal onde configura a mulher como a principal 
responsável pelo seu lar ou seja muitas mulheres enfrentam uma dupla jornada todos os dias, tendo que cuidar da casa, dos filhos e ter que ir trabalhar e muitas delas sofrem todos os tipos de abusos. Mesmo, tendo seus direitos de "igualdade" assegurado pela Constituição Federal de 1988, ainda encontramos muitas mulheres sendo submetidas a fazer tudo sozinha e tendo números altos de feminicídios, ao longo da pesquisa o que nos levou a pensar o quanto ainda temos que pedir permissão, pois, nós mulheres para participar de decisões importantes ou até mesmo para entrar em um universo que ainda é liderado por homens tem que criar algum regulamento ou até mesmo uma lei para desenvolver o nosso intelecto e principalmente para termos o nosso lugar de fala.

Se antes da pandemia era difícil para a mulher ter que conciliar os serviços domésticos, com estudo, trabalho e filhos, imagina em meio a uma pandemia em que nos obriga a ficarmos isolados por meses, temos que nos adaptar ao novo cenário que nos apresenta, em ter que nos habituar com a rotina do outro, como internet que não comporta com a demanda, por ter tanto aparelhos ligados ao mesmo tempo, vizinhos que não compreendem o momento acabam colocando som muito alto ao ponto de incomodar e atrapalhar a nova rotina, achando que está em período de férias prolongadas, inexistência de computadores suficiente para todos da casa, pois, como creches, escolas, faculdades estão fechadas, então, a rotina educacional ficou sendo remotamente, e como gerenciar tudo isso em meio a tantas transformações?

Assim, o trabalho remoto durante a pandemia vem acarretando sérios problemas, como é o caso de produção acadêmica, estudos realizados no contexto do projeto "Parent in Science" coordenado pela Prof. Dra ${ }^{\mathrm{a}}$. Fernanda Stanisçuaski da Universidade Federal do Rio Grande do Sul revelam que o número de publicação realizados por mulheres caiu consideravelmente, segundo a pesquisa, foram ouvidos mais de 5 mil pesquisadores de mestrados e doutorados que vem desenvolvendo suas atividades em home office. Dos que participaram da pesquisa foram $31 \%$ homens e $69 \%$ mulheres, dos que declararam que têm filhos foram $26 \%$ são homens e $74 \%$ são mulheres. A pesquisa está em andamento, pois, o período de isolamento social é considerado 
atípico, pois há inúmeras transformações de comportamento e a referida pesquisa vem monitorando a produtividade dos acadêmicos com perfil descrito (NEUMANN, et al. 2020).

É interessante que as mulheres no processo de sua ressignificação na conquista do seu lugar de fala em pleno o XXI tem que se privar de muitas coisas, pois em sua busca de qualificação profissional tem que enfrentar diversos obstáculos e muitas vezes tem que abrir mão de alguma oportunidade. A referida pesquisa divulgada pelo Parente in Science destaca bem o caminho percorrido das mulheres que tem filhos e principalmente como a sua produtividade caiu durante a pandemia.

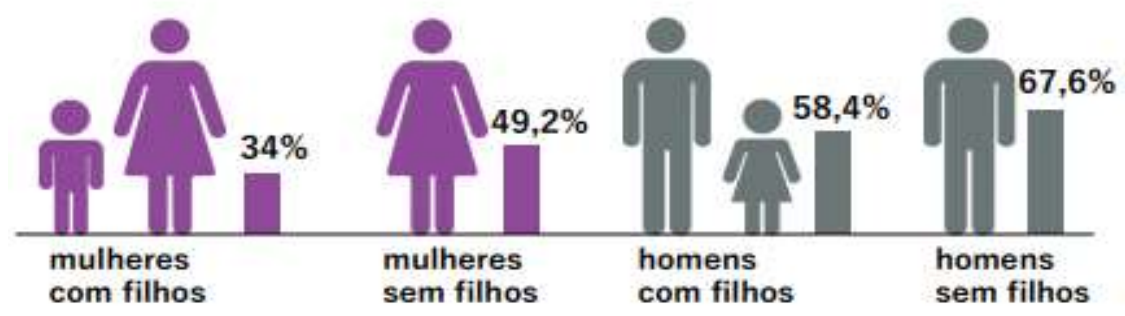

Fonte: NEUMANN, et al. 2020.

Conforme a imagem logo acima, mulheres com filhos não conseguiram entrar no ritmo acadêmico em meio a pandemia. Apenas 34\% conseguiram submeter artigos conforme seu cronograma. E 66\% não conseguiram submeter artigos conforme o planejado, um número bem alarmante, pois, a produção acadêmica de pesquisadoras é primordial para aquelas profissionais que tem interesse em participar de editais de projetos de pesquisa, processo de concurso público e conceituação de carreira.

É importante ressaltar que independente de mulheres acadêmicas ou não a questão é que as mulheres sempre sofreram para ter sua ascensão profissional, mesmo tendo mais estudos do que os homens e quando somos colocados em meio a uma guerra com um inimigo invisível Covid19, nos perguntamos quem está na linha de frente? Quem está com olhar mais atento a essa questão? E mais uma vez nos deparamos com dados relevantes divulgados recentemente pelo Fundo de População das Nações Unidas (UNFPA,2020), em escala global 
são 70\% as equipes da área da saúde e serviço social são integradas por mulheres

No Brasil não está sendo diferente, conforme o Conselho Nacional de Secretarias Municipais de Saúde (CONASEMS), divulgou dados do IBGE que afirma, dos 6 milhões de trabalhadores operantes nas repartições públicas e privadas da área da saúde 65\% são integrados ou liderados por mulheres. É super relevante discutirmos a presença das mulheres no campo da pesquisa, ciência, tecnologia e inovação, muito embora,fica evidente as barreiras que elas têm que enfrentar diariamente para conquistar o seu espaço em algumas áreas.

No decorrer da pesquisa, percebe-se que a história feminina é bem recente e que ainda tem muito o que ser conquistado, desse modo, a autora Ana Colling faz uma reflexão sobre essa trajetória pautada na invisibilidade feminina na história da humanidade.

[...] desde que a História existe como disciplina científica, ou seja, desde o século XIX, o seu lugar dependeu das representações dos homens, que foram, por muito tempo, os únicos historiadores. Estes escreveram a história dos homens, apresentada como universal, e história das mulheres desenvolveu-se à sua margem. Ao descreverem as mulheres, serem seus porta-vozes, os historiadores ocultaram-nas como sujeitos, tornaram-nas invisíveis. Responsáveis pelas construções conceituais, hierarquizaram a história, com os dois sexos assumindo valores diferentes; o masculino aparecendo sempre como superior ao feminino. (COLLING, 2004, p. 13).

Nessa perspectiva, é importante ressaltar que mesmo tentando silenciar as mulheres de toda forma não conseguiram o tal efeito de tornar as mulheres invisíveis, muito pelo contrário, as mulheres se uniram vem conquistando o seu espaço e provando que são capazes de ir muito além. Desta forma, Silva, 2012 reflete que:

[...] o mundo da ciência se estruturou em bases quase exclusivamente masculinas, ora excluindo as mulheres, ora negando as suas produções científicas, através de discursos e práticas nada neutros. Contudo, apesar dos mecanismos de exclusão, seja pelos processos formais que impediam por leis ou regulamentos o acesso das mulheres às universidades, pelos discursos científicos que, ao "naturalizarem" as diferenças entre homens e mulheres, 
determinavam os lugares sociais que os sujeitos deveriam ocupar de acordo com suas características biológicas, ou até mesmo pelos processos culturais de visibilização de mulheres cientistas ao longo da história, as mulheres, em maior ou menor representatividade, estiveram presentes e atuantes na história das ciências. (Silva, 2012, p. 20).

Desta forma, fica marcado a trajetória de luta das mulheres em diversos campos, cada um tem sua particularidade, mas, sempre esbarramos no mesmo ponto, o da exclusão da mulher. Mas, a história vem sendo contada com base de muitas conquistas e principalmente diálogos vêm sendo provocados através de artigos, relatórios e pesquisa que acontece dentro das universidades e sempre os diálogos são liderados por mulheres que buscam e mostram os direitos conquistados por séculos.

\section{As adversidades da mulher pesquisadora no decorrer da pandemia}

Partindo desse princípio a pandemia mostrou que nós mulheres lamentavelmente ainda são consideradas responsáveis pelo seu lar e principalmente quando concerne a cuidar dos filhos em ter que acompanhá-los, assistir as aulas, orientá-los a realizar as tarefas, as atividades domesticas e ainda cumprir agenda de docente, como também, não pode deixar o papel de pesquisadora, realmente não vem sendo fácil infelizmente temos que conciliar a essa nova realidade. Faz, mais de 90 dias em casa e tivemos que adaptar a nossa vida corrida para ser home office, e o problema não é só os afazeres domésticos e sim ao processo de adaptação, pois, com a pandemia nós mulheres, que tínhamos uma jornada diária considerada dupla agora com o isolamento social se tornou triplicada, pois, o nosso trabalho intensificou, como também, a responsabilidade e infelizmente o processo da pesquisa vai dando uma estacionada.

Hoje, além de mãe, pesquisadora, cientista, empreendedora e docente, realmente não tem sido fácil, mas, vem sendo reflexivo, pois, podemos refletir um pouco o momento que estamos vivendo e passamos observar que muitas coisas que dávamos importância se tornou irrelevante diante do caos provocado pela pandemia e ao mesmo tempo notamos que muitas pessoas não saíram das 
suas bolhas e pensam que isolamento social são férias prolongadas, como também, a importunação do bem estar coletivo quanto cidadãos, por que sua casa além de ser lar, agora virou escritório, creche, sala de aula, laboratório e nesse turbilhão de adversidades de convívio social temos que gerenciar bem e ainda praticar atividades que nos deixe saudável mentalmente.

O caos provocado pela Covid19 em que nos obrigou a ficar no isolamento social, fez com que nossa responsabilidade aumentasse, como também, nos tirou bruscamente da nossa zona de conforto e nos colocou em uma situação de impotência total diante de um vírus destruidor, onde vem, dizimando pessoas e deixando familiares órfãos, chegando a ser desesperador em ter que assistir todo esse sofrimento e não poder fazer nada, ficamos inerte, temos que aguardar o momento tão esperado de calmaria chegar. Paralelo as essas transformações de mundo, fomos obrigado a nos adaptar a essa nova realidade e continuar de onde paramos para dar seguimento ao que tinha sido planejado e como continuar diante de um vírus que nos deixou tão impactados?Como será o mundo depois que chegar à calmaria e/ou novo normal? Bem, quanto mulher, mestranda, cientista, empreendedora procurei a me adaptar à nova realidade de mundo, onde tudo ficou digital tão de repente e não vem sendo fácil, pois temos que trabalhar nossa mente pra esse novo cenário.

E com tantos fatores o mais difícil está sendo em reestruturar a rotina ao home office e ter que conciliar esse momento de trabalho, pesquisa e empreendedorismo com os familiares que muitas vezes não compreende que para termos resultado é preciso dedicação, disciplina e principalmente o tão prazeroso silêncio que a maioria das situações não há. Através das inúmeras reuniões, como também, consultoria estão acontecendo de forma remota, acaba compartilhando a rotina dos vizinhos onde evidencia som alto, discussão inesperada o que vem provocando a particular improdutividade como pesquisadora e empreendedora é importante ressaltar o emocional que tem sido afetado drasticamente. 
Corroborando com os achados de Dunker (2017) que diz: o paralelo tecnológico que pulveriza a construção e propagação de informação, causa um déficit narrativo na construção dos laços sociais.

\section{Reflexões finais}

Em momento de pandemia a ciência ganhou destaque globalmente e com elas os profissionais de saúde e pesquisadores, o que vem provocando inúmeras discussões sobre a origem do Covid19 e principalmente a importância do papel do pesquisador numa sociedade desenvolvida. Nessa mesma linha de pensamento ganha destaque as pesquisadoras que descobriram o genoma do novo Corona Vírus, a pesquisa foi composta por cinco mulheres e evidenciaram a estrutura do vírus em 48 horas. Mostra o quanto as mulheres são determinadas e não deixam de ir a busca do seu projeto de vida, conforme a Unesco, 2019 a classe de pesquisadoras mulher é composta por apenas $28 \%$.

Neste contexto, pesquisadoras trouxeram para o campo da ciência a discussão do papel da mulher nesse setor e enfatizando a importância da mulher nesse seguimento tão determinante para o futuro de uma sociedade.

A pandemia além de trazer o caos, trouxe consigo a possibilidade de muitos entrarem em período de reflexão, como também, evidenciar, quanto a trajetória de luta de muitas mulheres ainda faz a diferença e o quanto a nossa sociedade ainda é tão resistente a compreender que nós mulheres há anos estamos em luta e todos os dias recontamos a nossa história.

O número baixo de pesquisadoras mulheres que não conseguiram publicar durante a pandemia é de fato preocupante, pois avançamos muito, mas, precisamos divulgar o quanto nós mulheres ainda temos barreiras a enfrentar, principalmente quando somos mães em que a responsabilidade de educar, acompanhar todo o desenvolvimento humano do filho é apenas responsabilidade da mulher. 
Desta forma, autores enfatizam que a mulher que decide seguir uma carreira científica é levada a pensar duas vezes em escolher ser mãe ou ser cientista, em função da necessidade de conciliar a carreira com a maternidade. Contudo, as inspirações históricas puncionam as mulheres a continuarem lutando, no espaço da emancipação da voz, ultrapassando barreiras pessoais, científicas e partidárias.

\section{Referências}

ALCÂNTARA, S.; LIMA, M.C.P. O (im)possível do educar na cibercultura: reflexões psicanalíticas sobre educação, tecnologia e os desafios da docência na contemporaneidade. SCIAS Edu., Com., Tec., Belo Horizonte, v.1, n.1, p. 2-23, ago./dez. 2019

CANDIDO, M. R.; CAMPOS, L. A. Pandemia reduz submissões de artigos acadêmicos assinados por mulheres, Revista de Ciências Sociais, 2020.14 May 2020. Disponível em: http://dados.iesp.uerj.br/pandemia-reduz-submissoesde-mulheres/. Acesso em: 20 de julho 2020.

COLLING, Ana. A construção histórica do feminino e do masculino. In: STREY, Marlene; CABEDA, Sonia Lisboa; PREHN, Denise (Orgs.). Gênero e cultura: questões contemporâneas. Porto Alegre: EDIPUCRS, 2004. P. 13-38.

DEDONÉ, T.S. A Educomunicação e o processo de formação dos professores: ressignificando saberes. SCIAS Edu., Com., Tec., Belo Horizonte, v.1, n.1, p. 115126, ago./dez. 2019.

DUNKER, C. Intoxicação digital infantil. In: BAPTISTA, A.; JERUSALINSKY, J. Intoxicações eletrônicas: o sujeito na era das relações virtuais. Salvador: Álgama, 2017. p. 117-145.

IBQP (2018), “Empreendedorismo no Brasil: relatório executivo 2018. GEM (Global Entrepreneurship Monitor GEM)

LIMA, Bruno. Cinco pesquisadoras que sequenciaram o genoma do coronavírus. Março de 2020. Disponível em: https://www.correiobraziliense.com.br/app/noticia/brasil/2020/03/o8/intern a brasil,832797/conheca-as-5-pesquisadoras-que-sequenciaram-o-genoma-docoronavirus.shtml, Acessado em 14/07/2020.

MATOS, M. Pandemia COVID-19 e as mulheres. Boletim $N^{o} 11$ - Pandemia COVID-19 e as mulheres, Abril de 2020. Disponível em:

https://cienciapolitica.org.br/noticias/2020/04/boletim-11-pandemia-covid19-e-mulheres, Acesso em: 25 de Junho 2020.

NEUMANN, A. et al. PRODUTIVIDADE ACADÊMICA DURANTE A PANDEMIA: Efeitos de gênero, raça e parentalidade. Disponível em: https://www.parentinscience.com/ 
Acessado em 14/07/2020

PINTO, C.R.J. FEMINISMO, HISTÓRIA E PODER. Rev. Sociol. Polít., Curitiba, v. 18 , n. 36 , p. 15-23, jun. 2010.

SILVA, F.F. Mulheres na ciência: Vozes, tempos, lugares e trajetórias, Rio Grande do Sul. 2012, 147p.

WERMELINGER, M. et al. Feminilização do Mercado de Trabalho em Saúde no Brasil: focalizando a feminização. Divulgação em Saúde para Debate, Rio de Janeiro, n. 45, p. 54-70, maio 2010.

VIEIRA, et al. A guerra tem rosto de mulher: trabalhadoras da saúde no enfrentamento à Covid-19.Disponível em: http://anesp.org.br/todas-asnoticias/2020/4/16/a-guerra-tem-rosto-de-mulher-trabalhadoras-da-sade-noenfrentamento-covid-19. Acessado em 20/07/2020. 